March 25, 2008

\title{
Labor Retrenchment Laws and their Effect on Wages and Employment: A Theoretical Investigation
}

\author{
By \\ Kaushik Basu* \\ Gary S. Fields** \\ and \\ Shub Debgupta***
}

\begin{abstract}
Many countries have legislation which make it costly for firms to dismiss or retrench workers. In the case of India, the Industrial Disputes Act, 1947, requires firms that employ 50 or more workers to pay compensation to any worker who is to be retrenched. This paper builds a theoretical model to analyze the effects of such antiretrenchment laws. Our model reveals that an anti-retrenchment law can cause wages and employment to rise or fall, depending on the parametric conditions prevailing in the market. We then use this simple model to isolate conditions under which an antiretrenchment law raises wages and employment. In a subsequent section we assume that the law specifies exogenously the amount of compensation, $s$, a firm has to pay each worker who is being dismissed. It is then shown that as $s$ rises, starting from zero, equilibrium wages fall. However beyond a certain point, further rises in $s$ cause wages to rise. In other words, the relation between the exogenously specified cost to the firm of dismissing a worker and the equilibrium wage is $\mathrm{V}$-shaped.
\end{abstract}

JEL Classification: O15; O17; J32; J63.

Keywords: labor laws, retrenchment, severance pay, unemployment

Acknowledgements: The authors would like to thank Richard Freeman, Garance Genicot, Jeff Hammer, Costas Meghir, Yew-Kwang Ng, Martin Rama, and Tridip Ray for helpful comments and suggestions. The paper also benefited from seminar presentations at the World Bank, Washington, D.C.; ILO, Geneva; Presidency College, Calcutta; and WISE, Xiamen University, Xiamen. A part of the work on this paper was done when Kaushik Basu was visiting the Indian Statistical Institute, New Delhi, in spring 2007.

\footnotetext{
*Department of Economics, Cornell University, Ithaca, New York 14853. (kb40@cornell.edu)

** School of Industrial and Labor Relations, Cornell University, Ithaca, New York 14853. (gsf2@)cornell.edu)
}

**at Corporate Executive Board, 2000 Pennsylvania Avenue, NW, Washington, DC 2006. (debguptas@executiveboard.com) 


\section{Labor Retrenchment Laws and their Effect on Wages and Employment: A Theoretical Investigation}

\section{Introduction}

Many countries legislate guidelines or procedures to be followed, including compensation to be paid to the workers, in the event of their being dismissed or retrenched. At times, these laws virtually prohibit the dismissal of laborers, disregarding any contract that a worker and his or her employer may have signed at the time of employment. At times, the legislation includes some form of pre-determined severance compensation. This tendency to legislate conditions for compensation which override voluntary contracts, has been witnessed in many countries, with varying degrees of stringency. Some countries, such as India and France, are known for their strict antiretrenchment regulations. In the case of India, the Industrial Disputes Act, 1947, requires firms that employ 50 or more workers to pay a compensation, which is specified in the Act, to any worker who is retrenched. In addition, an amendment to the Act, which became effective in 1984, requires firms which employ more than 100 workers to actually seek prior permission from the government before retrenching workers. And, as Datta Chaudhuri (1994) has noted, the government seldom gives permission and, in general, places a lot of a priori restrictions on the terms for hiring and firing workers (see, also Mathur, 1989; Edgren, 1989; Papola, 1994) ${ }^{1}$.

What is interesting about such laws is how lay opinion on them is at divergence from the opinion of economists. The popular wisdom on this issue is that these anti- 
retrenchment laws help labor, but hurt the development process, as they force firms to maintain huge workforces that reduce their ability to make profit.

One problem with the conventional wisdom is that it fails to capture the fact that anti-retrenchment laws raise the effective cost of employing labor and, as a result, firms may hire fewer workers. Additionally, it is conceivable that, given the presence of such laws, some firms may not enter into production in the first place. Hence, the economists' view of this is often the opposite of the lay opinion: By burdening firms with the risk that they may not be able to fire their workers or that they will have to pay very large compensations in order to do so, the anti-retrenchment laws cause a decline in the demand for labor and thereby cause a lowering of wages and so ultimately hurt workers.

This paper builds a theoretical model to analyze whether anti-retrenchment laws can be expected to help workers or not. The model is a useful tool of analysis for nations like India, France, Italy and Zimbabwe, which have stringent anti-retrenchment laws that have come in for criticism and debate and, in some cases, calls for repeal. It can also be useful for countries, like eastern European ones and China, which have weak antiretrenchment laws and have debated strengthening these.

Our theoretical investigation reveals that the truth is more complicated than either of the two views mentioned above. In section 2 we first build a very simple benchmark model, in which there is no industry-wide risk but individual firms face stochastic shocks in each period which may cause fluctuations in the number of workers that they would ideally want to employ. We then consider two alternative legal regimes - one in which an employer cannot retrench workers once they are employed and another regime in which the employer can freely hire and fire. We show that even in such a simple model 
there is no unique effect on wages: an anti-retrenchment law can cause wages to rise or fall, and aggregate employment to rise or fall, depending on the parametric conditions prevailing in the market. We then use this simple model to isolate conditions under which an anti-retrenchment law raises wages and employment and conditions under which it lowers wages and employment.

In subsequent sections we progressively relax the assumptions of the benchmark model. Section 3 endogenizes industry size. Section 4 introduces an exogenously determined amount of compensation, $s$, that a firm has to pay each worker who is being dismissed. Then, $s=0$ and $s=\infty$ correspond to the two regimes in the benchmark model. In Section 4 we also model the dynamic optimization problem that each firm faces. By using a combination of algebra and geometry we demonstrate how the labor market equilibrium can be characterized very simply. The model is then used to demonstrate a paradoxical result: As $s$ rises, starting from zero, equilibrium wages fall (as expected). However beyond a certain point, further rises in $s$ cause wages to rise. In other words, the relation between the exogenously specified cost to the firm of dismissing a worker and the equilibrium wage that prevails in the market is V-shaped. We also use the model to comment on the possibility of frictional unemployment and the consequence of industry size being endogenously determined.

Among notable studies on this topic we would draw attention to papers by Lucas (1988), Bentolila and Bertola (1990), Hopenhayn and Rogerson (1993), Fallon and Lucas (1993), Anderson and Meyer (1994), Besley and Burgess (2004), and Basu (2006). Bentolila and Bertola (1990) use aggregate data from France, Germany, Italy and UK to calibrate their continuous-time stochastic model to analyze the labor demand of a single 
monopolist in the face of changing hiring and firing costs. Their results, based on a partial equilibrium analysis, were that dismissal costs actually raised long run employment. Their results were based on a specific calibrated model and are therefore applicable primarily to the four countries studied.

Anderson and Meyer (1994), using data on the United States, showed that if unemployment insurance taxes are seen as an adjustment cost for changes in labor size, then an increase in these taxes will decrease demand for labor in a high demand state, but will increase employment in a low demand state. In our paper we provide a theoretical validation for this observation and incorporate it into the anti-retrenchment setting.

Fallon and Lucas (1993), in an empirical study on the anti-retrenchment laws in Zimbabwe and India, showed that as the laws were strengthened (making it more difficult to layoff a worker), long-run demand for employees fell by 25.2 percent and 17.5 percent, respectively. They could not determine any significant reduction in wages as a result of the laws. In the case of India the point has been made time and again that rigid labor market legislation may have hurt India's overall growth and efficiency. The claim that is being forwarded in this paper is different. It is being argued that the legislation may have hurt the very constituency that it was meant to protect, to wit, labor. Hence, Kannan's (1994) observation that wages in the eighties have not kept pace with labor productivity and Ghose's (1994) finding that employment per unit of gross value added in manufacturing fell monotonically throughout the eighties (see, also, Dev, 2000) sit very well with the theoretical findings of this paper and the fact that India's labor market legislation was made more rigid in the eighties. ${ }^{2}$ In fact, data from Annual Survey of Industries, Government of India, show that, between 1982-83 and 1990-91, the number of 
workers employed in firms employing 100 to 199 workers fell by 28.5 percent and the number of workers employed in firms employing over 200 workers fell by $43 \%$. It should be recalled that in 1984 new laws were enacted making retrenchment by firms employing over 100 workers especially difficult. It is not surprising that firms would respond to this by cutting down on labor intensity or switching over to contract labor.

In this paper, we abstract away from specific institutional aspects of job security legislation and of the industrial labor markets in different countries, and use a parsimonious version, which we believe capture pertinent aspects of the economic environment. We show that the special case, which is nested within a general model, produces theoretically ambiguous labor market effects. Thus, the seemingly contradictory results obtained in the literature, where in some cases more restrictive antiretrenchment laws cause a fall in employment versus the cases where they result in a rise in employment, can be obtained from the single model presented in this paper for different parameter values.

It is hoped that these results will not only provoke further empirical work, but give us pause for thought in our effort to draft policy and legislation to improve labor standards and, more generally, labor welfare.

\section{Labor Market Equilibria With or Without Retrenchment}

In this section we model the likely effects of anti-retrenchment laws. We shall, in particular, consider two alternative legal regimes: one in which employers are free to retrench workers at will and another in which no retrenchment, whatsoever, is allowed. 
These will be referred to as the "free retrenchment (F) regime" and "no retrenchment (N) regime", respectively. Reality is, of course, more complicated, where retrenchment laws take shades of gray instead of being black and white. However, formalizing the two polar cases helps us fix our ideas and gives us some benchmarks to use. Once we have formalized these we shall go on in Section 4 to formulate an intermediate case with severance compensation.

Our aim in this section is to model the kinds of equilibria that arise in the labor market under the $\mathrm{F}$ and $\mathrm{N}$ regimes. In particular, we want to study the impact of alternative legal regimes on wages and employment. Since anti-retrenchment laws are enacted with the aim of enhancing the welfare of labor it is worth checking formally whether this actually happens, once everyone has had time to adjust to the new laws. As stated in intuitive terms earlier, it turns out that anti-retrenchment laws do not always help workers. The formal model below illustrates how, given certain parametric configurations, a switch from regime $\mathrm{F}$ to regime $\mathrm{N}$ can actually lower the wage and aggregate employment. In other words, if such parametric configurations occur, the antiretrenchment legislation would, paradoxically, work to the laborers' detriment. It is shown that there are also parametric configurations where the non-paradoxical result occurs, that is, workers' wages rise.

As a base case, let us suppose there are $n$ identical firms, each endowed with a production function as follows:

$$
x=\varphi f(L) ; \quad f^{\prime}(L)>0, f^{\prime \prime}(L)<0
$$

$\mathrm{L}$ is the amount of labor used by the firm, $x$ the firm's output, and $\varphi$ a stochastic variable which takes values of 1 and 0 with probability $p$ and (1-p) respectively. To keep the 
algebra simple we model this stochastic shock as being independent across firms and across time, thereby ruling out industry-wide fluctuations and intertemporally correlated shocks. ${ }^{3}$ Then, appealing to the law of large numbers, we assume that in each period a randomly selected $p n$ firms have $\varphi=1$ and $(1-p) n$ firms have $\varphi=0 .{ }^{4}$ We ignore the integer problem here by assuming that $p n$ is an integer.

It is also assumed, for the time being, that in each period or year each firm gets to see $\varphi$ before making its hiring decision. If for a certain firm $\varphi=1$, we shall describe that as a good year for the firm. A bad year is one in which $\varphi=0$. There are different ways of interpreting $\varphi$. It could represent input and technology shocks that firms receive. In a bad year $\varphi=0$ and the firm is unable to produce. Alternatively, as suggested in footnote 3 , we could think of $\varphi$ as denoting the price of the product. The firms are scattered in different geographical locations. In each location demand for the product can be high or low. When demand is high, the price of the product in one and demand is low, it is zero.

Let us first model the F regime. Each firm is free to hire and lay off workers as it sees fit. In a good year, a firm's demand for labor is given by solving the following problem:

$$
\underset{\mathrm{L}}{\operatorname{Maximize}} \mathrm{f}(\mathrm{L})-w \mathrm{~L} \text {. }
$$

The first order condition is given by:

$$
f^{\prime}(L)=w
$$

Since $\mathrm{f}^{\prime \prime}(\mathrm{L})<0$, the function $\mathrm{f}^{\prime}(\mathrm{L})$ can be inverted and written as $\mathrm{g}(\mathrm{w})$. Hence, in a good year, with market wage $w$, a firm's demand for labor is given by

$$
\mathrm{L}=\mathrm{g}(\mathrm{w})
$$


In a bad year since $\varphi=0$, a firm's demand for labor is obviously 0 . Hence in the F regime, the aggregate demand for labor is given by png(w).

Let the aggregate supply function of labor be given by $s(w)$ such that $s^{\prime}(w) \geq 0$. Assuming that the usual equilibrating forces are free to operate in the $F$ regime, the market equilibrium is one in which aggregate labor demand equals aggregate labor supply. Clearly $\mathrm{w}^{\mathrm{F}}$ is the equilibrium wage in the F-regime if and only if

$$
\operatorname{png}\left(\mathrm{w}^{\mathrm{F}}\right)=\mathrm{s}\left(\mathrm{w}^{\mathrm{F}}\right) \text {. }
$$

Figure 1, below, depicts this equilibrium. The equilibrium amount of labor demanded and supplied is denoted by $\mathrm{L}^{\mathrm{F}}$.

Let us now depict the equilibrium in an N-regime. We are therefore considering an economy in which there is a law requiring that once a firm hires a laborer it cannot retrench him.

Since we already know what the aggregate supply curve is, namely, s(w), all we have to do is to work out the demand for labor in this regime and then look for the wage that equates demand and supply.

A short-cut method for working out the demand for labor in an N-regime is to assume that each employer must decide how much labor to hire before $\varphi$ is revealed. What we are claiming is that, in an $N$-regime, this is a good approximation of the case where the firms have to choose how many workers to hire, after seeing the value of $\varphi$. The reason why this method works is that apart from the first period, the employer will (in an N-regime) be effectively stuck with a certain amount of labor in all periods without knowing each period's realization of $\varphi$. So unless the future is too heavily discounted, the fact that $\varphi$ is known in one period, namely, the first period is of negligible importance. 
Hence, our method causes an error, but of a sufficiently small order, so that it may be ignored. This is demonstrated in Appendix 1.

For a risk-neutral firm that does not know the value of $\varphi$ in advance, in the Nregime, the firm's problem is to maximize expected profits

$$
\underset{\mathrm{L}}{\operatorname{Maximize}}[\mathrm{pf}(\mathrm{L})-\mathrm{wL}]
$$

Hence, by the first-order condition we get

$$
f^{\prime}(L)=w / p .
$$

Hence, the firm's demand for labor is given by:

$$
\mathrm{L}=\mathrm{g}(\mathrm{w} / \mathrm{p})
$$

where $g($.$) is, as before, the inverse of \mathrm{f}^{\prime}(\mathrm{L})$.

Because each firm is identical ex ante, the aggregate demand for labor is $n g(w / p)$. So $\mathrm{w}^{\mathrm{N}}$ is an equilibrium wage in an $\mathrm{N}$-regime if the amount of labor demanded equals the amount supplied at that wage:

$$
\operatorname{ng}\left(\mathrm{w}^{\mathrm{N}} / \mathrm{p}\right)=\mathrm{s}\left(\mathrm{w}^{\mathrm{N}}\right)
$$

On inspecting (4) and (7) it appears possible that $\mathrm{w}^{\mathrm{N}}$ may exceed $\mathrm{w}^{\mathrm{F}}$, be less than $\mathrm{w}^{\mathrm{F}}$, or be the same as $\mathrm{w}^{\mathrm{F}}$ depending on the value of $\mathrm{p}$ and the shape of the $\mathrm{g}($.$) function. This is$ easily proved by considering the following special case of the above model. Let the production function, $\mathrm{f}(\mathrm{L})$, be the following quadratic one.

$$
f(L)=(A / B) L-L^{2} / 2 B
$$

with $\mathrm{A}, \mathrm{B}>0$. As long as $\mathrm{L}$ is less than $\mathrm{A}$ (and we shall throughout confine attention to such cases), (8) is a reasonable production function, satisfying $\mathrm{f}^{\prime}(\mathrm{L})>0$ and $\mathrm{f}^{\prime \prime}(\mathrm{L})<0$. It is easy to verify that (8) implies that the firm has a linear labor demand function

$$
g(w)=A-B w .
$$


Using (9) the aggregate demand for labor in the economy is given by

$$
\mathrm{L}^{\mathrm{F}}=\mathrm{pn}[\mathrm{A}-\mathrm{Bw}]
$$

in the F-regime, and by

$$
\mathrm{L}^{\mathrm{N}}=\mathrm{n}[\mathrm{A}-\mathrm{Bw} / \mathrm{p}]
$$

in the N-regime. These two labor demand curves are illustrated in Figure 2. One sees that they necessarily cross. The point of intersection is denoted by $\mathrm{E}$.

Suppose we begin with a world in which retrenchments are freely allowed.

Hence, the aggregate demand curve of labor is given by the steeper demand curve in Figure 2, marked 'Demand in F-regime'. If the laws of the land are changed and firms are not allowed to retrench labor, the effect on wages depends on where the initial equilibrium was. Suppose first that the labor supply curve was like the curve marked SS in Figure 2, so that the equilibrium lay to the left of $E$, at the point labeled $E^{\mathrm{F}}$ in the figure. Then a switch to the N-regime would move the equilibrium from $\mathrm{E}^{\mathrm{F}}$ to $\mathrm{E}^{\mathrm{N}}$, thereby lowering wages and employment, and hurting workers. On the other hand, if the labor supply curve is to the right of $\mathrm{E}$, as for curve $\mathrm{S}^{\prime} \mathrm{S}^{\prime}$, and the equilibrium was at $\mathrm{E}^{\mathrm{F}^{\prime}}$, a switch to the N-regime moves the equilibrium to $\mathrm{E}^{\mathrm{N}^{\prime}}$, raising wages and employment, and benefiting workers. The special case of $p=1 / 2$ is analyzed in the following footnote. ${ }^{5}$

Thus far we have assumed that the labor supply function, s(w), remains unaffected by regime switches between no-retrenchment $(\mathrm{N})$ and free-retrenchment $(\mathrm{F})$ regimes. At one level this is as it should be, since, in the aggregate, there is no involuntary unemployment in our model. But, if we assume that workers mind the transaction cost of switching jobs, the same wage $w$ is more attractive to the worker when it comes with a no-retrenchment clause. Extending our assumption that a better offer 
elicits a greater labor supply, we may assume we have two supply functions, $\mathrm{s}^{\mathrm{F}}($.) and $\mathrm{s}^{\mathrm{N}}($.$) , for the two regimes, and that, for all \mathrm{w},{ }^{6}$

$$
s^{\mathrm{F}}(\mathrm{W}) \leq \mathrm{s}^{\mathrm{N}}(\mathrm{W}) .
$$

This complicates the analysis in Figure 2 . If the original equilibrium were at $\mathrm{E}^{\mathrm{F}}$, then a switch in regime to no-retrenchment causes an even more precipitous fall in the wage, since SS shifts right as the regime changes. However the effect on employment is now

ambiguous. If $\mathrm{S}^{\mathrm{N}}$ is sufficiently to the right of $\mathrm{S}^{\mathrm{F}}$, employment may actually rise. Moreover, the welfare-effect of the switch in regime is also ambiguous, since the same wage in an N-regime gives greater welfare to the worker (by virtue of a lower transactions cost). Hence a lower wage in an N-regime may or may not give lower total welfare.

Similarly if the original equilibrium were at $\mathrm{E}^{\mathrm{F}^{\prime}}$, a change of regime to noretrenchment will now exert a smaller upward pressure on wages. Indeed wages may now fall. This will happen if the rightward shift of $S^{\prime} S^{\prime}$ is sufficiently large.

So far we have shown that the special case of the simple model is theoretically ambiguous. Our aim now is to generalize this model in stages.

\section{Endogenizing Industry Size}

In the above exercise we assumed industry size to be fixed at $n$. Let us now suppose, as is often assumed in models of perfect competition with free entry, that there is a very large number of firms and, in equilibrium, industry size gets determined endogenously by using a zero expected profit condition. 
To avoid some trivial equilibria with zero production, we shall make a small modification to the function $\mathrm{f}(\mathrm{L})$. We assume that there exists some positive number, $\mathrm{K}$, such that, for all $\mathrm{L} \leq \mathrm{K}, \mathrm{f}(\mathrm{L})=0$, and for all $\mathrm{L}>\mathrm{K}, \mathrm{f}^{\prime}(\mathrm{L})>0, \mathrm{f}^{\prime \prime}(\mathrm{L})<0$. In other words, the total product (TP) curve, $f(L)$, the marginal product (MP) curve, $f^{\prime}(L)$, and the average product (AP) curve, $\mathrm{f}(\mathrm{L}) / \mathrm{L}$, looks as in Figure 3 below.

Now define, as before,

$$
g(w) \equiv \underset{(L)}{\arg \max }[f(L)-w L]
$$

How do the equilibria in the $\mathrm{F}$ and $\mathrm{N}$ regimes compare?

Maintaining the assumption of free entry of firms, consider first a freeretrenchment $(\mathrm{F})$ regime. If the wage is $\mathrm{w}$, in the F-regime each firm earns a profit of

$$
f(g(w))-w g(w)
$$

New firms will keep entering the industry as long as the above expression is greater than zero. Likewise if the expected profit is less than zero we do not have an equilibrium since firms will be exiting from the industry. In other words, in an F-regime, an equilibrium wage is $\underline{w}$, where this is defined implicitly by,

$$
f(g(\underline{w}))-\underline{w} g(\underline{w})=0 \text {. }
$$

$\underline{\mathrm{w}}$ is illustrated in Figures 3 and 4.

Now consider the no-retrenchment $(\mathrm{N})$ regime. A firm in an $\mathrm{N}$-regime facing wage $\mathrm{w}$, expects to earn

$$
\mathrm{pf}(\mathrm{L})-\mathrm{wL}
$$

if it hires L workers. As Appendix 1 shows, this can be justified in a limiting sense even in a dynamic model. Define

$$
\ell(w) \equiv \underset{L}{\arg \max }[p f(L)-w L] .
$$


It should be evident from the previous section that this function is the same as $g(w / p)$.

If the wage is $\mathrm{w}$ in an $\mathrm{N}$-regime each firm expects to earn a profit of:

$$
\operatorname{pf}(\ell(w))-w \ell(w) .
$$

Hence, using a justification as above, we find that in an N-regime, $w$ is an equilibrium wage if:

$$
\operatorname{pf}(\ell(\underline{\underline{w}}))-\underline{\underline{w}} \ell(\underline{w})=0 .
$$

We now have the following:

Claim: $\mathrm{w}<\underline{\mathrm{w}}$ and $\ell(\mathrm{w})=\mathrm{L}(\underline{\mathrm{w}})$.

To prove this claim observe that to define $\mathrm{w}$ as opposed to $\underline{\mathrm{w}}$ we simply have to pretend that the production function $f(L)$ is instead $p f(L)$. Whatever we do with $f(L)$ to get to $\underline{w}$, we have to do with $\mathrm{pf}(\mathrm{L})$ to get to $w$. It is obvious from Figure 3 that

$$
\underline{w}=\max [f(L) / L] .
$$

Hence,

$$
\underset{=}{\mathrm{w}}=\max [\mathrm{pf}(\mathrm{L}) / \mathrm{L}] .
$$

Since $p<1$, it follows that $w<\underline{w}$. Clearly, the value of $\mathrm{L}$ that maximizes $\mathrm{f}(\mathrm{L}) / \mathrm{L}$ also maximizes $\mathrm{pf}(\mathrm{L}) / \mathrm{L}$. Hence, $\ell(\underline{w})=\mathrm{g}(\underline{\mathrm{w}})$. This establishes the above claim.

In Figure 4, let $\underline{w}$ and $w$ be as shown and let $\mathrm{s}(\mathrm{w})$ be the aggregate supply curve of labor. Hence aggregate employment in the F-regime will be $\underline{L}^{\mathrm{F}}$ and in the $\mathrm{N}$-regime $\underset{=}{\mathrm{L}^{\mathrm{N}}}$ as shown. 
What happens to industry size as we switch regimes from $\mathrm{N}$ to $\mathrm{F}$ ? The number of

firms in the $N$ and $F$ regimes are given by, respectively, $L^{N} / \ell(w)$ and $\underline{L}^{F} / g(\underline{w})$. Since by the above claim $\ell(\underline{w})=\mathrm{g}(\underline{\mathrm{w}})$ and given $\underline{\mathrm{L}}^{\mathrm{F}}>\underline{\mathrm{L}}_{=}^{\mathrm{N}}$, it follows that

$$
\frac{L^{F}}{g(w)}>\frac{L^{N}}{\ell(w)} .
$$

Therefore, as expected, the industry is larger under the F-regime, and so too are wages and employment. Therefore, in a country in which, for reasons of law, institutions or technology, there is free entry into industries, a no-retrenchment regime is unequivocally worse for the workers.

\section{Model with Worker Compensation and Optimization over Time}

\subsection{The Case of No Frictional Unemployment}

In this section we generalize the preceding model by assuming that, as in reality, the government does not ban retrenchments nor make them totally free, but instead insists that when a firm lays off a worker, it makes a severance payment of $s$ to the worker. In this model we also make the inter-temporal decision of the firm explicit. Suppose a firm, after one or more good years, finds itself in a bad year. It can then retrench workers by paying them s or it can hold on to the workers in the hope that a good year will come up soon and thereby save the cost of the severance payment. This is the decision problem that the firm has to solve through dynamic optimization. 
As before, we shall assume that there are $n$ identical firms each facing a production function as in equation (1). As before, a 'good year' is one in which $\varphi=1$ and a 'bad year' one in which $\varphi=0$. Let us denote the representative firm's discount factor by $\delta=1 /(1+r)$, where $0<\delta<1$

Now, let $\mathrm{L}$ and $\mathrm{M}$ be the number of workers that a firm employs in a good year and in a bad year, respectively. Denoting the present value of a firm's profits, starting from a good year, by $G$ and the present value of a firm's profits, starting from a bad year, by $\mathrm{B}$, we get the following two equations

$$
\begin{gathered}
\mathrm{G}=\mathrm{f}(\mathrm{L})-\mathrm{wL}+\delta[\mathrm{pG}+(1-\mathrm{p})\{-\mathrm{s}(\mathrm{L}-\mathrm{M})+\mathrm{B}\}] \\
\mathrm{B}=-\mathrm{wM}+\delta[\mathrm{pG}+(1-\mathrm{p}) \mathrm{B}]
\end{gathered}
$$

To understand $\mathrm{G}$, note that if we start with a good year, then the firm's profit in that year is $\mathrm{f}(\mathrm{L})-w \mathrm{~L}$. In the following year, if the firm is lucky and has another good year (which occurs with probability p) then from that year on, the firm's expected present value is $\mathrm{G}$. This explains the third term on the right-hand side of equation (12), $\delta \mathrm{pG}$. Next note that if the next year is bad, then the firm spends $s(\mathrm{~L}-\mathrm{M})$ in severance payments and thereafter expects the payoff of $B$. Hence the last term, $\delta(1-p)\{-s(L-M)+B\}$. Equation (13) is likewise easy to interpret, remembering that profit in a bad year is $-\mathrm{wM}$, because the firm produces nothing, but must pay for the wages. ${ }^{7}$ Solving (13) for B we have,

$$
\mathrm{B}=[\delta \mathrm{pG}-\mathrm{wM}] /[1-\delta(1-\mathrm{p})]
$$

Inserting this in equation (12) and rearranging terms, we get

$$
\mathrm{G}=\left[\frac{1-\delta(1-p)}{1-\delta}\right][\mathrm{f}(\mathrm{L})-w \mathrm{~L}-\delta(1-\mathrm{p}) \mathrm{sL}]+\frac{\delta(1-\mathrm{p})}{1-\delta}[\mathrm{s}(1-\delta(1-\mathrm{p}))-\mathrm{w}] \mathrm{M}
$$


Let us assume that a firm comes into existence in a good year. ${ }^{8}$ Hence, the firm's problem is to choose $\mathrm{L}$ and $\mathrm{M}$ to maximize $\mathrm{G}$ subject to $0 \leq \mathrm{M} \leq \mathrm{L}$. From equation (14), it is clear that the relation between $G$ and $M$ is affine. Hence, it is obvious that the firm will set $\mathrm{M}=0$, if $\mathrm{s}(1-\delta(1-\mathrm{p}))<\mathrm{w}$ and it will set $\mathrm{M}=\mathrm{L}$, if $\mathrm{s}(1-\delta(1-\mathrm{p}))>\mathrm{w}$.

Suppose now $s(1-\delta(1-p))<w$. From the above paragraph it is clear that the firm will choose $\mathrm{M}=0$. Inserting this in (14), we can work out the firm's first-order condition for maximizing $\mathrm{G}, \frac{\partial \mathrm{G}}{\partial \mathrm{L}}=0$, to be as follows:

$$
f^{\prime}(L)=w+\delta(1-p) s .
$$

Next suppose $s(1-\delta(1-p))>w$. Then the firm sets $M=L$. Inserting this in (14)

and working out the first-order condition, $\frac{\partial \mathrm{G}}{\partial \mathrm{L}}=0$, we get

$$
f^{\prime}(L)=\frac{W}{1-\delta(1-p)}
$$

Finally, when $s(1-\delta(1-p))=w, M$ can be any value between 0 and $L$ and $\frac{\partial G}{\partial L}=0$ turns out to be the same as (15).

To sum up, the quantities of labor demanded by firms in good and bad years (that is, respectively, $\mathrm{L}$ and $\mathrm{M}$ ) are given as follows.

$$
\begin{aligned}
& {[\mathrm{s}(1-\delta(1-p))<w] \Rightarrow\left[M=0 \text { and } L \text { is chosen so that } \mathrm{f}^{\prime}(\mathrm{L})=\mathrm{w}+\delta(1-\mathrm{p}) \mathrm{s}\right]} \\
& {[\mathrm{s}(1-\delta(1-\mathrm{p}))>\mathrm{w}] \Rightarrow\left[\mathrm{M}=\mathrm{L} \text { and } \mathrm{L} \text { is chosen so that } \mathrm{f}^{\prime}(\mathrm{L})=\mathrm{w} /\{1-\delta(1-\mathrm{p})\}\right]} \\
& {[\mathrm{s}(1-\delta(1-\mathrm{p}))=\mathrm{w}] \Rightarrow\left[\mathrm{M} \in[0, \mathrm{~L}] \text { and } \mathrm{L} \text { is chosen so that } \mathrm{f}^{\prime}(\mathrm{L})=\mathrm{w}+\delta(1-\mathrm{p}) \mathrm{s}\right]}
\end{aligned}
$$


Equations (17), (18) and (19) tell us what each firm's demand for labor in a good and bad year will be, given the wage, $w$, and severance payment, $s$. Our next task is to solve for $\mathrm{w}$ and check the effect of varying $\mathrm{s}$ on the equilibrium wage and employment.

Let us write the solution from equations $(17)-(19)$ as $\mathrm{L}(\mathrm{w}, \mathrm{s})$ and $\mathrm{M}(\mathrm{w}, \mathrm{s})$. We will treat these as functions though we know that in some non-generic special cases $\mathrm{M}(\mathrm{w}, \mathrm{s})$ is non-unique. The aggregate demand for labor in any single period is

$$
\operatorname{pnL}(w, s)+(1-p) n M(w, s)
$$

For simplicity, let us take labor supply to be perfectly inelastic at $\mathrm{N}$. That is, no matter what the wage, the supply of labor equals $\mathrm{N}$.

In equilibrium w must be such that aggregate labor demand equals aggregate labor supply:

$$
\operatorname{pnL}(w, s)+(1-p) n M(w, s)=N
$$

We can now solve (20) to get the equilibrium wage as a function of the severance payment:

$$
\mathrm{w}=\mathrm{w}(\mathrm{s}),
$$

the properties of which are derived below.

In Figure 5, let $\mathrm{ABC}$ be the marginal product of labor curve, $\mathrm{f}^{\prime}(\mathrm{L})$. The marginal cost of labor, MC, is given by the last terms in (17) - (19):

$$
\mathrm{MC}= \begin{cases}\mathrm{w}+\delta(1-\mathrm{p}) \mathrm{s}, & \text { if }[1-\delta(1-\mathrm{p})] \mathrm{s} \leq \mathrm{w} \\ \mathrm{w} /\{1-\delta(1-\mathrm{p})\}, & \text { otherwise }\end{cases}
$$

Given the marginal product function, in a good year a representative firm demands labor up to the point where marginal product equals marginal cost. Hence, the good year demand for labor, $\mathrm{L}$, by a representative firm as a function of $\mathrm{MC}$ is given by the line $\mathrm{ABC}$. 
To analyze the firm's demand for labor in a bad year, first mark the severance payment, $\mathrm{s}$, on the $\mathrm{y}$-axis. This is the amount the firm will have to pay each worker it lays off. Note that, if $\mathrm{s}<\mathrm{MC}$, it is cheaper to pay the severance payment than employ existing workers, and therefore $\mathrm{M}=0$. This is shown as the dotted line sA. However, if $\mathrm{s}>\mathrm{MC}$, the workers will be retained as it is more expensive to layoff workers than hiring them this period, therefore $\mathrm{M}=\mathrm{L}$. Hence the bad year demand for labor, $\mathrm{M}$, as a function of $\mathrm{MC}$ is given by the line $\mathrm{AsBC}$.

The left-hand panel in the same figure shows how the wage, $w$, translates into MC. Given a wage, w, the MC may be read off by moving up from $w$ to the line marked ZYO and then going horizontally to the y-axis.

To see why $\mathrm{MC}=\mathrm{s}$ where the two curves intersect, note that at the point of intersection

$$
\frac{w}{1-\delta(1-p)}=w+\delta(1-p) s
$$

It is easy to juggle this equation and show that when this equation holds, s must be equal to the left-hand term (and therefore also the right-hand term). Hence $\mathrm{s}=\mathrm{MC}$.

It is also worth taking note the Z-curve is a vertical shift of the $45^{\circ}$ line from the origin and as s increases the $\mathrm{Z}$-curve moves up.

The aggregate demand curve for labor is easily constructed from the right-hand panel of Figure 5 and is shown in the right-hand panel of Figure 6. In Figure 6, ab is the pn-times horizontal blow-up of the line $\mathrm{ABC}$ in Figure 5, and ac is the $\mathrm{n}$ times horizontal blow-up of $\mathrm{ABC}$. The aggregate demand depends on the size of the severance payment. If it is $\mathbf{s}$, then the aggregate labor demand is adec. It it is $\underline{\underline{s}}$ then it is aghc. The lines 
marked $X$ and $Z$ are the same as the two lines in the left-hand panel of Figure 5. Recall that the line $\mathrm{Z}$ moves down as $\mathrm{s}$ becomes smaller and coincides with the $45^{\circ}$ ray when $\mathrm{s}=0$.

Superimpose the aggregate supply curve in this figure. This is shown as the vertical line through N. The relation between $s$ and $w$ is now easily read off Figure 6. Clearly if $s=\underline{s}$, the equilibrium wage is $\underline{w}$. If $s=s$, the equilibrium wage is $w$. As $s$ rises from $\underline{s}$ to $s$, the wage rises from $\underline{w}$ to $\mathrm{w}$. To understand this observe that the aggregate demand curve for labor makes a discontinuous jump from the ab curve to the ac curve at $\mathrm{MC}=\mathrm{s}$. Hence, as long as $\mathrm{s}$ happens to be between $\underline{\mathrm{s}}$ and $\mathrm{s}$, supply equals demand exactly at $\mathrm{MC}=\mathrm{s}$. Since the $\mathrm{X}$ and $\mathrm{Z}$ intersect at a height of $\mathrm{s}$ and $\mathrm{X}$ is unchanged as s changes, for all $\mathrm{s}$ between $\underline{\mathrm{s}}$ and $\underset{s}{\mathrm{~s}}$, equilibrium wage must be between $\underline{\mathrm{w}}$ and $\underset{=}{\mathrm{w}}$. If $\mathrm{s}$ rises above $\mathrm{s}$, the wage remains fixed at $\underset{=}{\mathrm{w}}$ since supply equals demand at $\mathrm{MC}=\underset{=}{\mathrm{w}}$. If $\mathrm{s}$ falls below $\underline{\mathrm{s}}$, the equilibrium $\mathrm{MC}$ clearly remains at $\underline{\mathrm{s}}$, but the equilibrium wage rises. Thus if $\mathrm{s}=0$, equilibrium occurs at $\mathrm{g}, \mathrm{MC}=\underline{\mathrm{s}}$ and the wage $=\mathrm{w}^{\circ}$. It follows that the w(s) curve looks as in Figure 7.

Whether $\mathrm{w}^{\mathrm{o}}$ exceeds $\mathrm{w}$ or not depends on the parameters of the model. But as Figure 7 shows, if the severance payment is zero the wage is quite high. As s rises, w falls. But after a certain point as s rises, w rises. Hence, the response of the equilibrium wage, $\mathrm{w}$, to the statutory severance payment, $\mathrm{s}$, is $\mathrm{V}$-shaped or, more vividly and depending a bit on your hand-writing, lower-case-b-shaped. 
Intuitively, what is happening is this. When $\mathrm{s}$ is very low, firms retrench workers and make the severance payment whenever they do not need them. So, if s rises, w must fall to ensure that aggregate labor demand remains unchanged. Aggregate labor demand has to be unchanged in equilibrium because labor supply is perfectly inelastic. As s continues to rise, beyond a point, firms become indifferent between retrenching and holding on to their workers. For further rises in s, w must rise to keep firms indifferent between retrenching and not retrenching workers. Finally, when s becomes sufficiently large, there is no retrenchment; so further increases in s have no consequence; and $\mathrm{w}$ remains unchanged.

\subsection{The Case of Frictional Unemployment}

Up to now we did not discuss who gets the severance payment. We could either assume that government collects it as a kind of tax or the worker gets it as compensation. If it is the latter, then being dismissed is always desirable from a worker's point of view, since equilibrium always being at full employment, the worker gets immediately absorbed by the labor market and, in addition, he gets the severance payment.

To avoid such a phenomenon, let us introduce some frictional unemployment in

the model. Assume that once a worker is laid-off, he needs to spend one period searching before he finds a new job.

Let $\mathrm{E}$ be the number of people employed in each period. Given the assumption that frictional unemployment lasts one period, it follows that if (1-p) workers get retrenched in each period, then (1-p)E people are unemployed (and searching for new jobs) in each period. Since $\mathrm{N}$ is the total labor force, it must be that 


$$
N=E+(1-p) E,
$$

from which we have

$$
\mathrm{E}=\mathrm{N} /(2-\mathrm{p})
$$

Therefore, if $\mathrm{s}<\mathrm{w} /\{1-\delta(1-\mathrm{p})\}$, from (17), we know that the fraction (1-p) of the labor force gets retrenched in each period. Hence, (21) holds in that case.

To see what the equilibrium looks like in that case, suppose $\mathrm{s}=\underline{\mathrm{s}}$ (in Fig. 6 and 8). By $(21), E=N /(2-p)$. Draw a vertical line at $N /(2-p)$ as shown in Figure 8. Equilibrium, in the figure, occurs at $\mathrm{k}$. Hence the equilibrium wage is $\mathrm{w}^{*}$ and the total unemployment in the economy is $\mathrm{N}-\mathrm{N} /(2-\mathrm{p})=\mathrm{N}(1-\mathrm{p}) /(2-\mathrm{p})$. If $\mathrm{s}$ is lowered below $\underline{\mathrm{s}}$, unemployment will remain unchanged, but the equilibrium wage will rise.

The reader may also note that once we allow for frictional unemployment of the kind just described we may have a model with multiple equilibria: one with low wage, full employment, and another with high wage, frictional unemployment and retrenchment.

\section{Conclusion}

In the context of the recent protests in France, against its government's effort to make hiring and firing workers easier - or adopting what is often, euphemistically, called 'flexible' labor laws - and in the context of the ongoing debate in India about repealing some of its strongly protective labor laws-it has been argued in popular discourses that flexible labor laws could help the economy but at the cost of worker welfare, especially the welfare of organized labor. What this paper tries to show is that flexible labor laws 
can be in the interest of all laborers-that is, easier firing rules can increase employment and wages of all workers. The word 'can' is however important, because this need not always be so. There are contexts where the adoption of more flexible laws can hurt workers. This theoretical finding shifts our main task to determining under what conditions workers are better off with less protection. A large part of this paper was devoted to isolating the conditions. It was shown, for instance, that all workers would be better off with more flexible labor laws if entry of new firms into industry happened to be easy.

Our model also demonstrates that in a legal regime where the government exogenously specifies the compensation to be paid to a worker who is being retrenched, the relation between the size of this compensation and the equilibrium wage rate is Vshaped. Thus, paradoxically, beyond a certain level, further increases in the exogenously specified level of compensation increases labor welfare.

This theoretical investigation paves the way for empirical work and also further analytical research. Among extensions that will be interesting to pursue are the incorporation of stochastic shocks which are correlated across firms, and so have industry-wide effects; strategic interactions between governments, firms and unions; and the effects of partial unionization. In deciding whether a particular country will be better off relaxing or making more stringent it's rules of firing workers, it will be important to do empirical work to decide if the nation falls into categories, identified in the paper, where we know how the law could affect wages and employment and, hence, labor welfare. 


\section{Appendix 1}

This appendix demonstrates the claim made in Section 2 concerning aggregate labor demand in an N-regime with an infinite horizon.

Suppose a firm takes the decision concerning how much labor to employ only after the value of $\varphi$ has been revealed. Hence, there are two alternative scenarios for which we have to solve the firm's problem: $\varphi=1$ or $\varphi=0$. Let the firm's discount factor be a constant $\delta$. If the firm employs $L$ units of labor in each period, the present value of its profits will be

$$
\begin{aligned}
& {\left[\varphi f(L)+\delta p f(L)+\delta^{2} \operatorname{pf}(L)+\ldots\right]-\left[w L+\delta w L+\delta^{2} w L+\ldots\right]} \\
& =\varphi f(L)-\operatorname{pf}(L)+\operatorname{pf}(L) /(1-\delta)-w L /(1-\delta) .
\end{aligned}
$$

Maximizing this with respect to the choice of $\mathrm{L}$, we get the following first order condition

$$
\left.f^{\prime}(L)=w /[\varphi-p)(1-\delta)+p\right] .
$$

If we wanted to work out the $\mathrm{N}$-regime case in this manner we would have to replace (5) with (A1.1) and proceed with the exercise in Section 2 with this replacement.

Note however that a law which prevents retrenchment makes significant difference only if the firm's discount factor, $\delta$, is large. If the next period is unimportant to the firm (i.e. $\delta=0$ ) then clearly the firm's demand for labor is unaffected by whether regime $\mathrm{F}$ or $\mathrm{N}$ is in place. To study the effect of a regime switch in its extremity we therefore need to consider large $\delta$. Let us therefore consider the case where $\delta \rightarrow 1$. In that case the denominator in (A1) goes to $\mathrm{p}$ :

$$
(\varphi-p)(1-\delta)+p \rightarrow p \text {, as } \delta \rightarrow 1 .
$$

Therefore in the limit (as $\delta \rightarrow 1$ ), (A1) becomes 


$$
f^{\prime}(L)=w / p .
$$

But this is exactly equation (5). Hence (6) can be thought of as an expression for labor demand in the $\mathrm{N}$-regime, if there were virtually no discounting of the future. 


\section{References}

Anderson, Patricia M. and Bruce D. Meyer (1994), 'The Effects of Unemployment Insurance Taxes and Benefits on Layoffs Using Firm and Individual Data', National Bureau of Economic Research Working Paper, no. 4960.

Bardhan, Pranab (1983), 'Labor-Tying in a Poor Agrarian Economy: A Theoretical and Empirical Analysis', Quarterly Journal of Economics, Vol. 98, no. 3, 501-514.

Basu, Kaushik (2006), 'Labor Laws and Labor Welfare in the Context of the Indian Experience,' in A. de Janvry and R. Kanbur (eds.), Poverty, Inequality and Development: Essays in Honor of Erik Thorbecke, New York: Springer.

Besley, Tim and Robin Burgess (2004), 'Can Labor Regulation Hinder Economic Performance? Evidence from India', Quarterly Journal of Economics, 119 (1), 91-134.

Bentolila, Samuel and Guiseppe Bertola (1990), 'Firing Costs and Labor Demand: How Bad is Eurosclerosis?' Review of Economic Studies, Vol. 57, 61-79.

Datta Chaudhuri, Mrinal (1994), 'Labour Markets as Social Institutions in India', CDE Working Paper No. 16, Delhi School of Economics.

Dev, S. Mahendra (2000), 'Economic Liberalization and Employment in South Asia', Economic and Political Weekly, vol. 35, Jan 8 and 15.

Dreze, Jean and Anindita Mukherjee (1989), 'Labor Contracts in Rural India: Theories and Evidence, in: S. Chakravarty ed., The Balance Between Industry and Agriculture in Economic Development: Proceedings of the Eighth World Congress of the International Economic Association, Delhi, India, Vol. 3 St. Martin's Press, New York.

Edgren, Gus, ed. (1989), Restructuring Employment and Industrial Relations: Adjustment Issues in Asian Enterprises, I.L.O-ARTEP, New Delhi.

Fallon, Peter R. and Robert E.B. Lucas (1991), 'The Impact of Changes in Job Security Regulations in India and Zimbabwe, The World Bank Economic Review, Vol. 5, no. $3,395-413$.

Fallon, Peter R. and Robert E.B. Lucas (1993), 'Job Security Regulations and the Dynamic Demand for Industrial Labor in India and Zimbabwe, Journal of Development Economics, Vol. 40, 241-273.

Ghose, Ajit (1994), 'Employment in Organized Manufacturing in India', Indian Journal of Labor Economics, vol. 37. 
Hopenhayn, Hugo and Richard Rogerson (1993), 'Job Turnover and Policy Evaluation: A General Equilibrium Analysis', Journal of Political Economy, Vol. 101, no. 5, 915-938.

Kannan, K.P. (1994), 'Leveling Up or Leveling Down? Labour Institutions and Economic Development in India', Economic and Political Weekly, Vol. 29, July 23.

Lucas, Robert E.B. (1988), 'India's Industrial Policy', in: Robert E.B. Lucas and Gustav F. Papanek, eds., The Indian Economy, Westview Press, Boulder, Colorado.

Mathur, Ajeet N. (1989), 'The Effects of Legal and Contractual Regulations in Employment in Indian Industry', in: Gus Edgren, ed., Restructuring Employment and Industrial Relations: Adjustment Issues in Asian Enterprises, ILO - ARTEP, New Delhi.

Meng, Xin (2000), Labour Market Reform in China, Cambridge University Press, Cambridge, U.K.

Papola, T.S. (1994), 'Structural Adjustment, Labor Market Flexibility and Employment', Indian Journal of Labor Economics, vol. 37.

Rama, Martin (1999), 'Public Sector Downsizing: An Introduction', World Bank Economic Review, vol. 13, 1-22.

Ray, Debraj (1998), Development Economics, Princeton University Press, Princeton, New Jersey. 


\section{Figure 1}

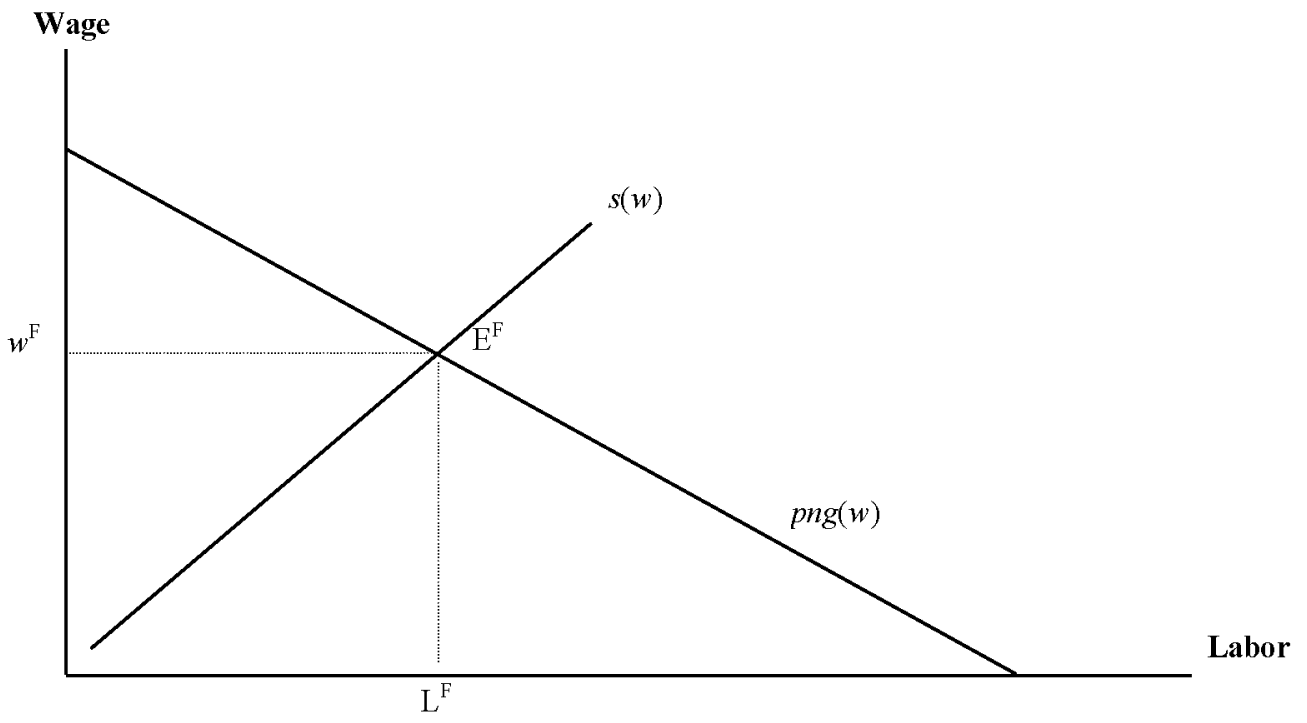

\section{Figure 2}

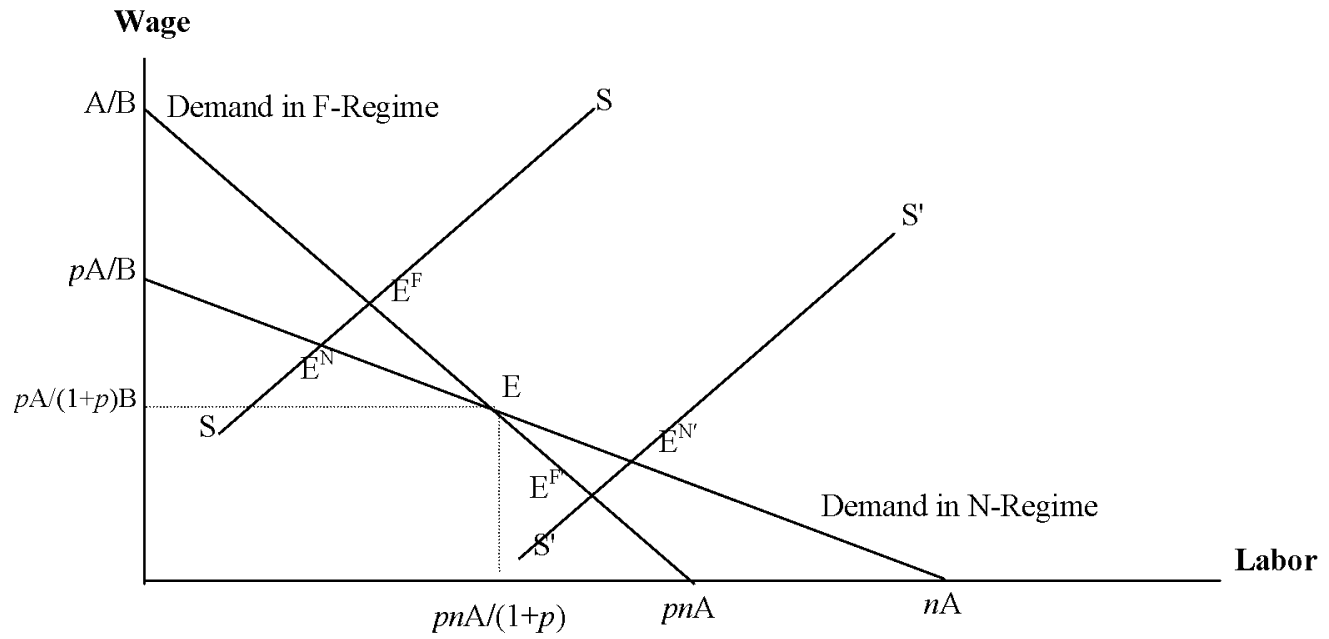


Figure 3
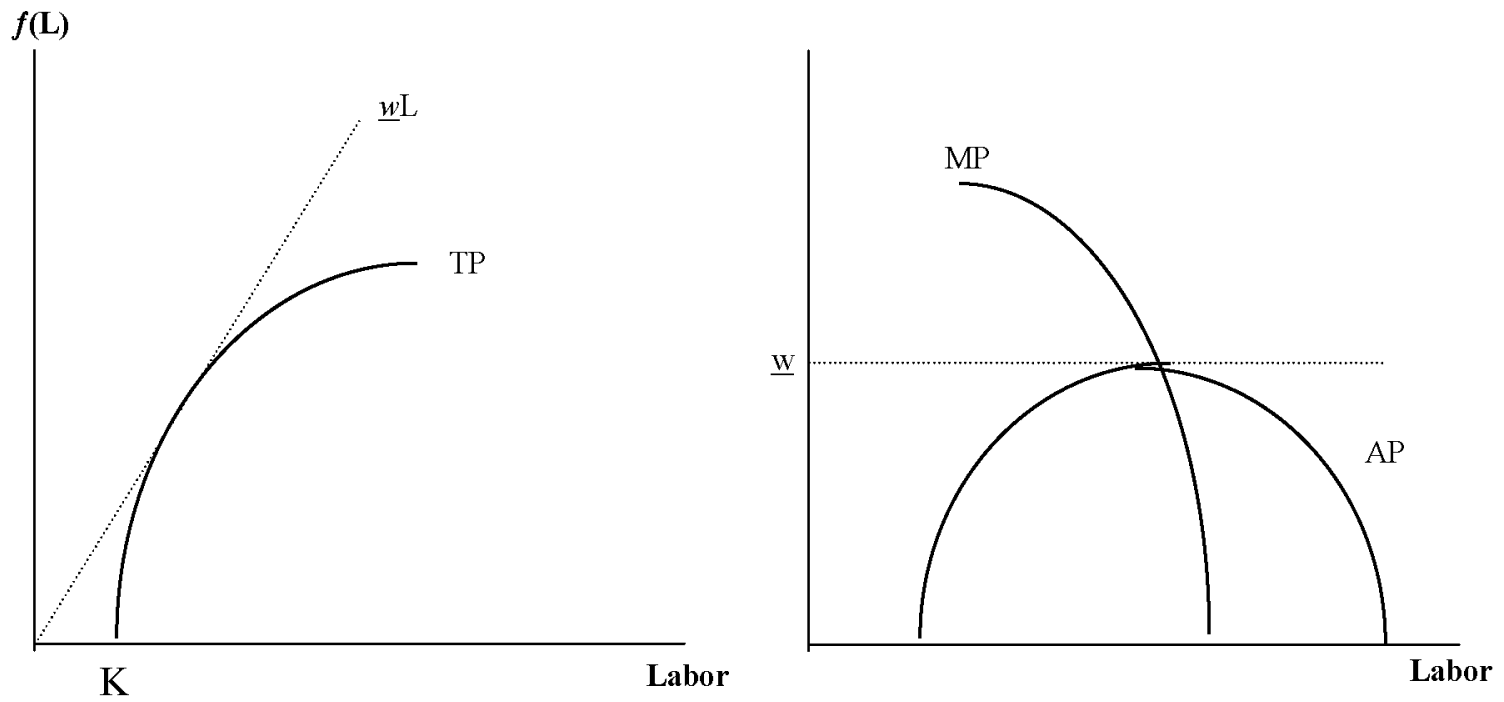

\section{Figure 4}

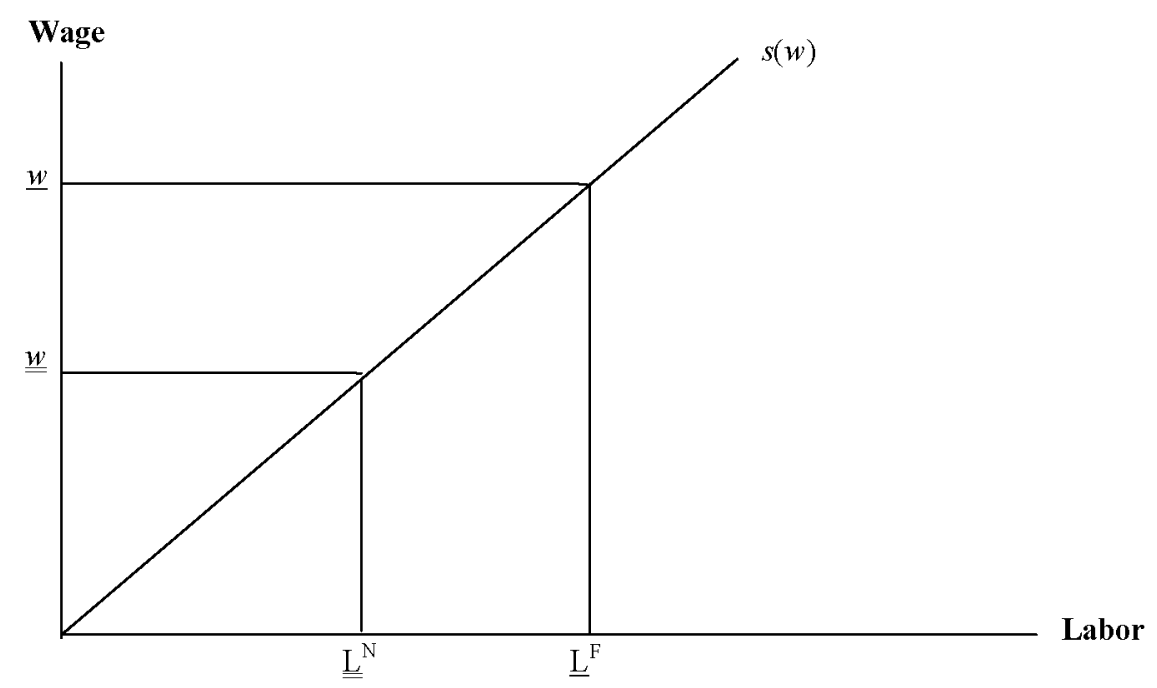




\section{Figure 5}

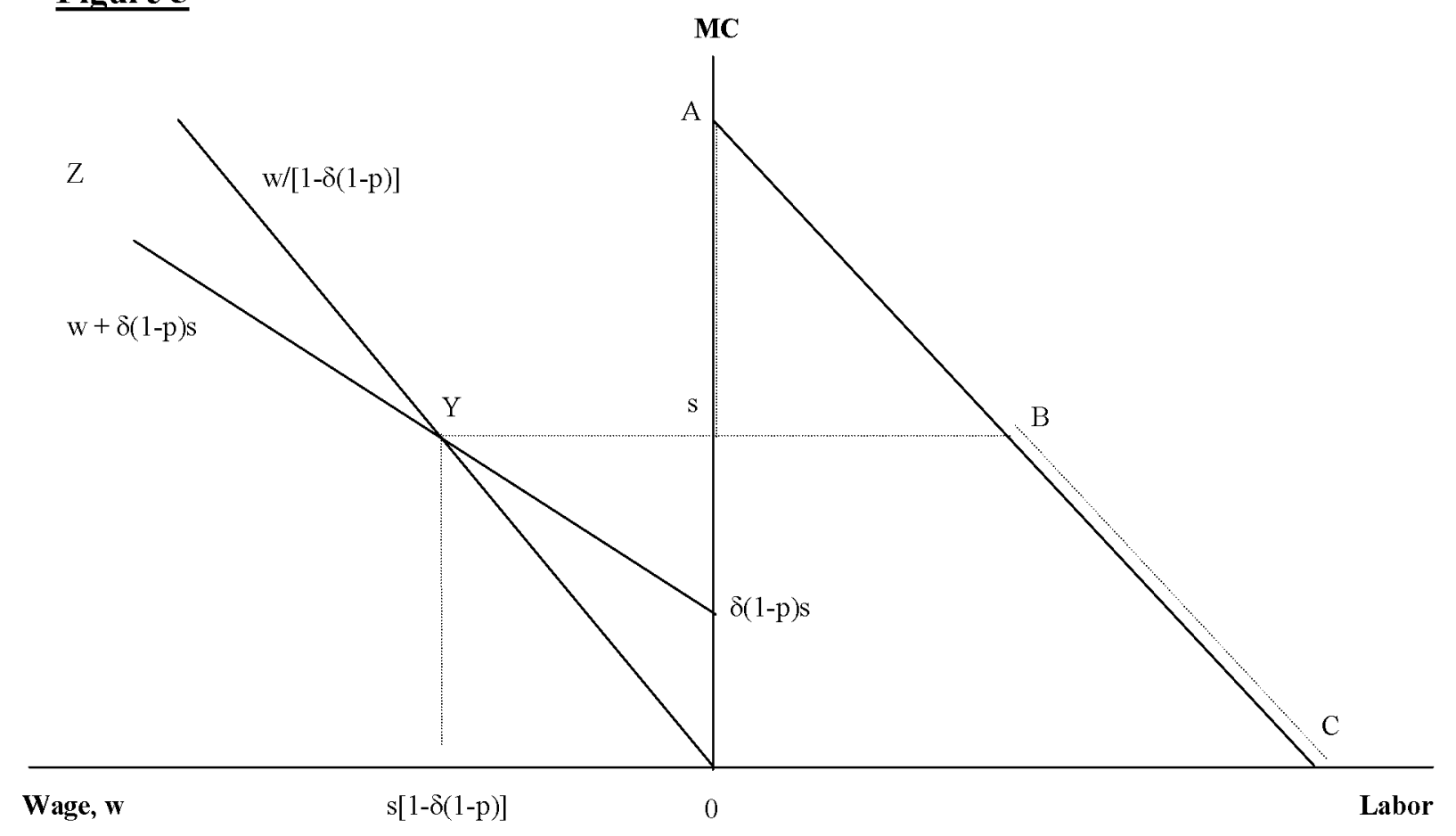

\section{Figure 6}

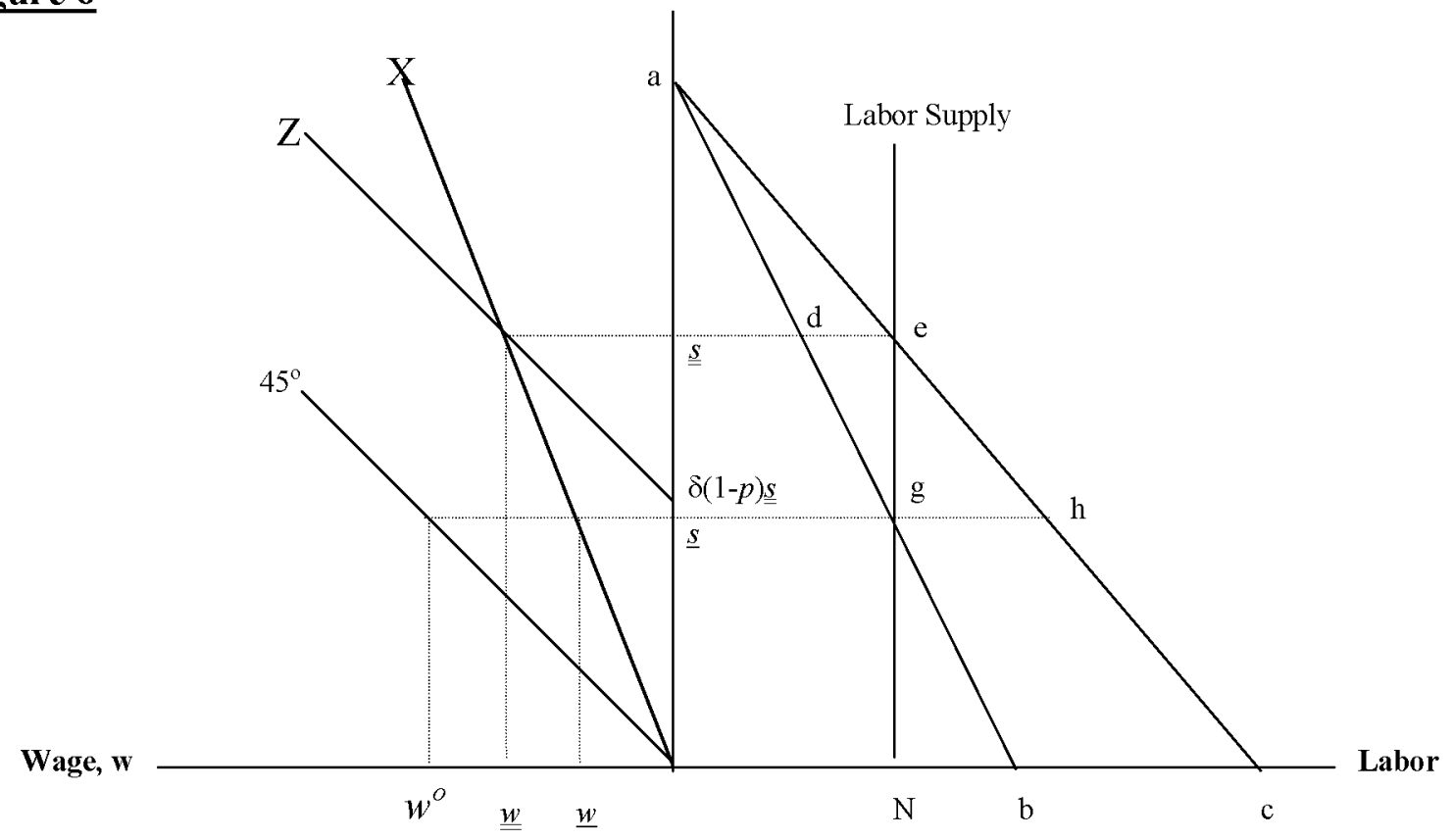


Figure 7

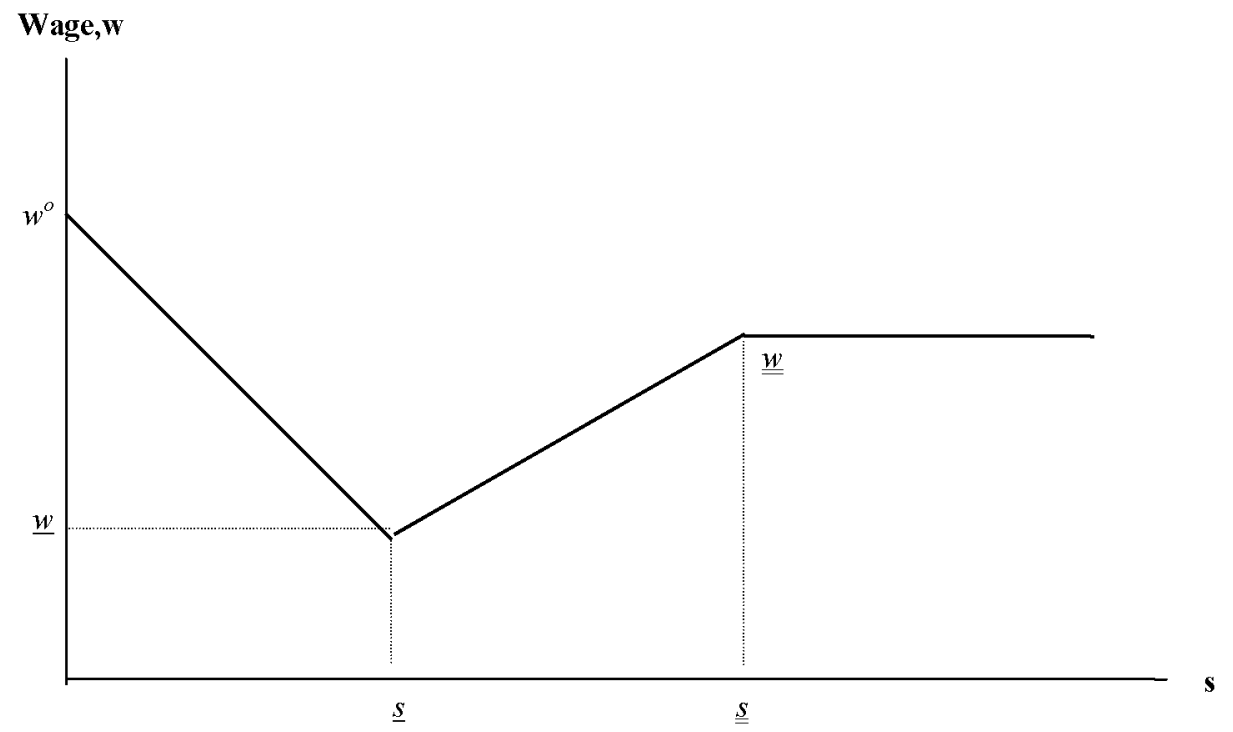

Figure 8

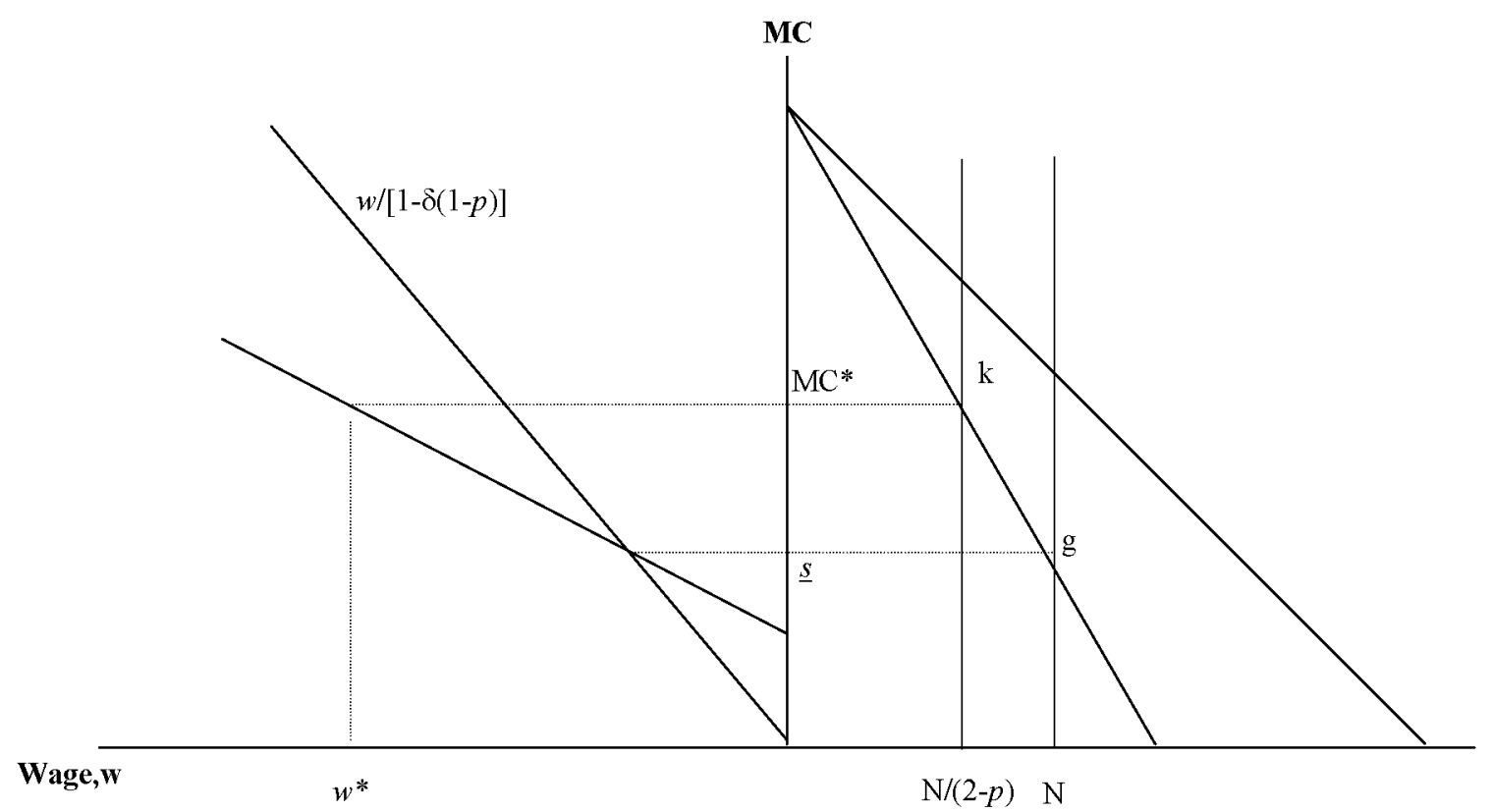




\section{FOOTNOTES}

${ }^{1}$ It is worth noting that the state governments of India are allowed to amend this legislation of the central government, within certain limits, since labor laws belong to what are called 'concurrent list' policies in India. Hence, there are some inter-state variations that have appeared over the years (Besley and Burgess, 2004).

${ }^{2}$ One matter that we do not go into explicitly but is important for assessing worker welfare in developing and transition economies is the problem of employment in public sector concerns. There are interesting parallel questions that arise in that context concerning over-staffing and retrenchment. Some of the practical problems arising in that context are discussed in Rama (1999). Commenting on state-owned enterprises in China, Meng (2000) has drawn our attention to the important fact that restrictions on labor policy, such as controls on retrenchment, arise not just from the law but often from the prevalent political and social culture.

${ }^{3}$ This is in contrast to models involving seasonality, in which aggregate demand for labor fluctuates from lean season to peak season. While such models are quite common in the development literature (see, for instance, Bardhan, 1983; Dreze and Mukherjee, 1989; and Ray, 1998), they pertain typically to the agricultural sector. In a model of the manufacturing sector, such as ours, it is not unreasonable to think of fluctuations in demand for the product of particular firms caused by shifts in demand from one segment of the industry to another. Our model may be thought of as a stylized description of this. It is not very difficult to incorporate correlated shocks in the model, but given the limited 
objective of the present paper, we have preferred to keep this simple. A more sophisticated model would allow for idiosyncratic and correlated shocks.

${ }^{4}$ It is worth noting that we could, instead of assuming $\mathrm{n}$ firms, have assumed that there is a continuum of firms, spanning, say, the interval $[0,1]$. In that case we would get the same result without having to use the law of large numbers.

${ }^{5}$ Let $p=1 / 2$. By filling in this number in Figure 2, we get a very well-specified rule. If, in an F-regime, the equilibrium wage is more than one-third the wage at which demand for labor goes to zero, then and only then does a law that bans labor retrenchment lower wage and employment and work to the detriment of workers. It is interesting to note that this "one-third rule" does not depend on the values of A and B and is also immune to different specifications of the labor supply curve. Nevertheless, it is a special rule for a special class of models. Our aim in deriving the rule is not to present it as a general result, but to illustrate that even when there is full employment and the welfare effects can be judged purely in terms of wage rates, the goodness or badness of an antiretrenchment law is theoretically ambiguous.

${ }^{6}$ In case we were working with a Lewis-type perfectly-elastic labor-supply function, the worker's preference for avoiding transactions cost would imply that the supply curve in the N-regime is below the supply curve in the F-regime. The analysis thereafter proceeds in the usual manner.

${ }^{7}$ In deriving these expressions it is important to treat the firm's decision to employ $\mathrm{L}$ and M workers in, respectively, the good and bad years as given. Otherwise, if the very first year is a bad one and $\mathrm{M}$ is positive the firm will be tempted to not employ any one in that 
year and then onwards employ $\mathrm{L}$ and $\mathrm{M}$ depending on if it is a good year or a bad year. If we want to give the firm this leeway, then we will need to distinguish between two kinds of B, namely, B': the present value of the firm's profits starting from a bad year, which is however not the first year in the firm's life and B": the present value of the firm's profits starting from a bad year, which is also the first year in the firm's life. B" looks like B in equation (13) but without the $-w M$ term. Since the B that appears in (12) will have to be B', our analysis here remains unaffected by introducing this additional complication.

${ }^{8} \mathrm{We}$ are making this assumption purely for reasons of simplicity. It is easy to alter this and check that the essential results remain unchanged if we abandon this assumption. 